\title{
Erratum
}

\section{EXACT SOLUTION OF THE SIMPLIFIED HUBBARD MODEL}

\author{
PAVOL FARKAŠOVSKÝ \\ Czech. J. Phys. 43 (1993), No. 2, 159 \\ Received 26 April 1993
}

Equation (3) on p. 161 should read

$$
H=-t \sum_{i j}^{\prime} c_{i}^{+} c_{j}+U \sum_{i} w_{i} c_{i}^{+} c_{i}
$$

